
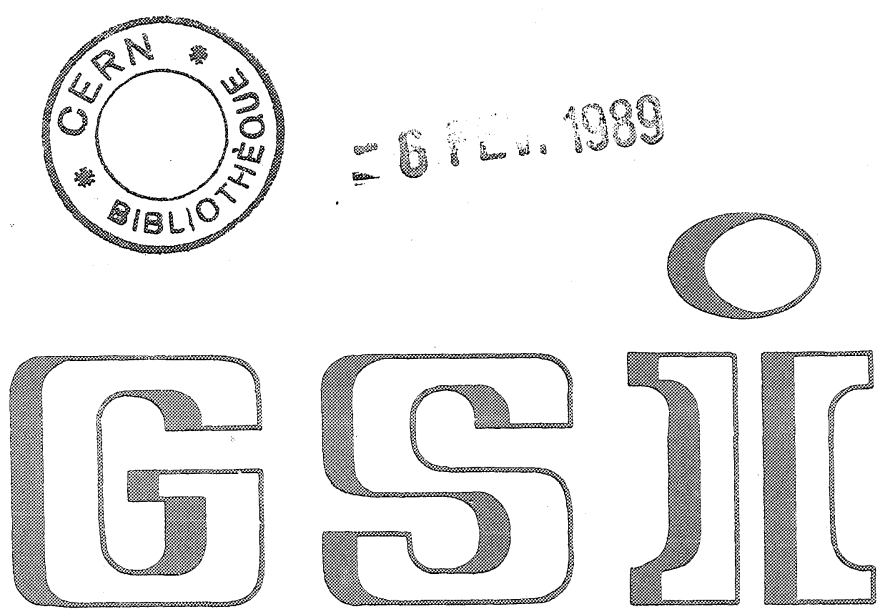

GSI-89-05 PREPRINT JANUAR 1989

\title{
CORRELATIONS OF NEUTRAL PIONS IN ULTRA- RELATIVISTIC HEAVY ION COLLISIONS
}

T. Peitzmann, R. Albrecht, T.C. Awes, C. Baktash, P. Beckmann,

F. Berger, R. Bock, G. Claesson, G. Clewing, L. Dragon, A. Eklund, R.L. Ferguson, A. Franz, S. Garpman, R. Glasow, H.A. Gustafsson, H.H. Gutbrod, J. Idh, K.H. Kampert, B.W. Kolb, P. Kristiansson, I.Y. Lee, H. Löhner, I. Lund, F.E. Obenshain, A. Oskarsson,

I. Otterlund, S. Persson, F. Plasil, A.M. Poskanzer, M. Purschke, H.G. Ritter, R. Santo, H.R. Schmidt, T. Siemiarczuk, S.P. Sorensen,

E. Stenlund, G.R. Young

\section{CERN LIBRARIES, GENEVA}

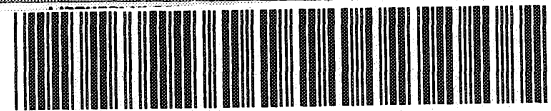

CM-P00062833 

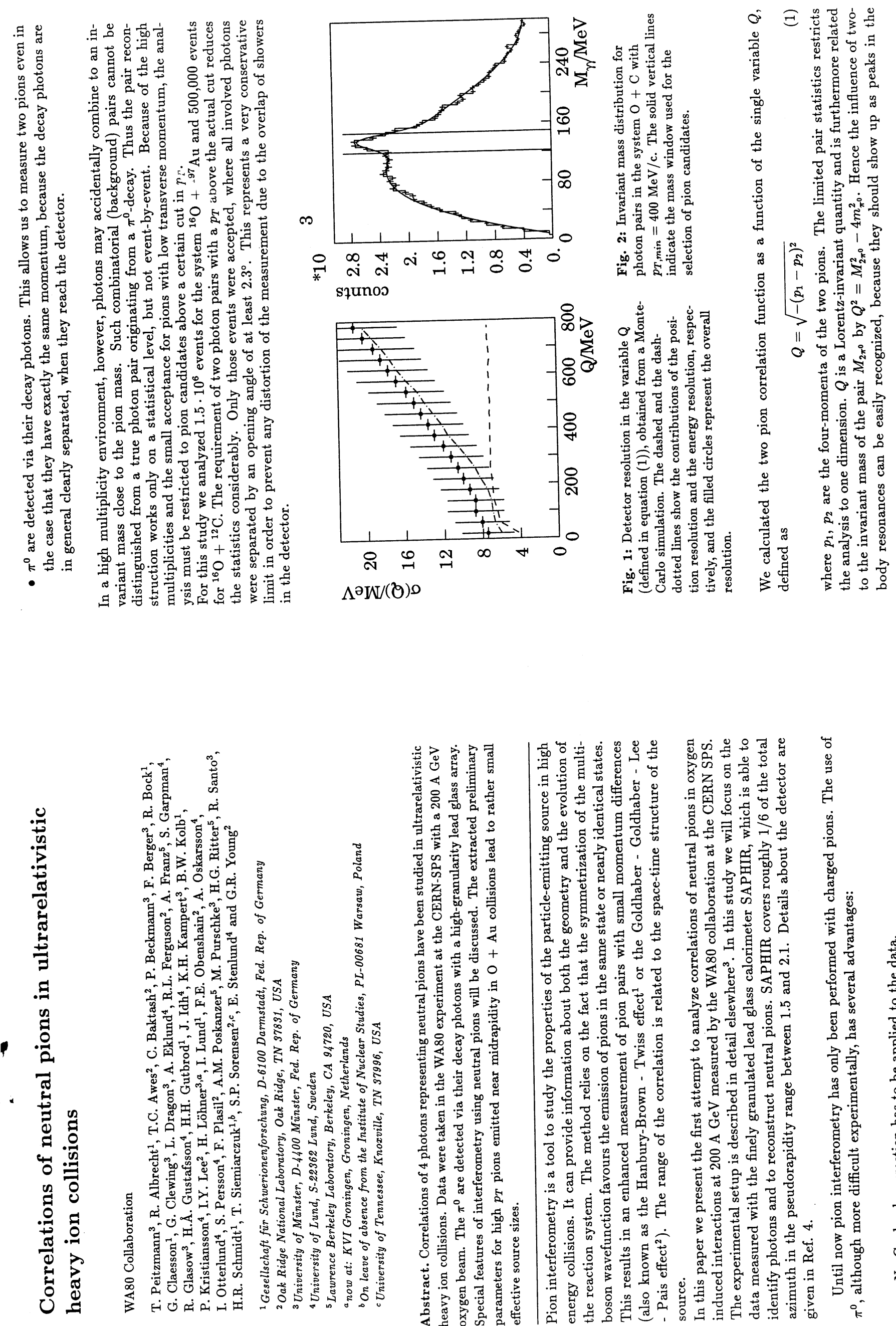

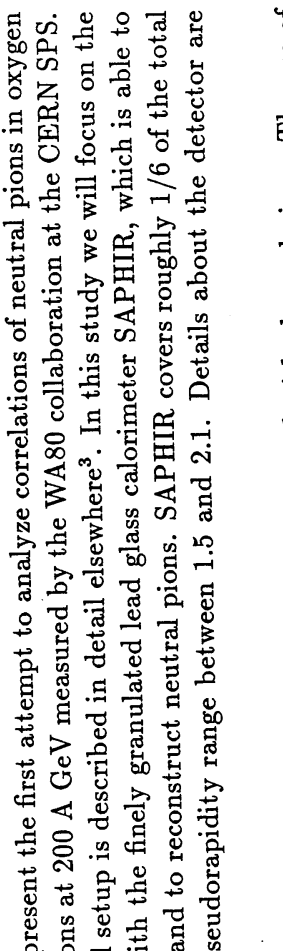

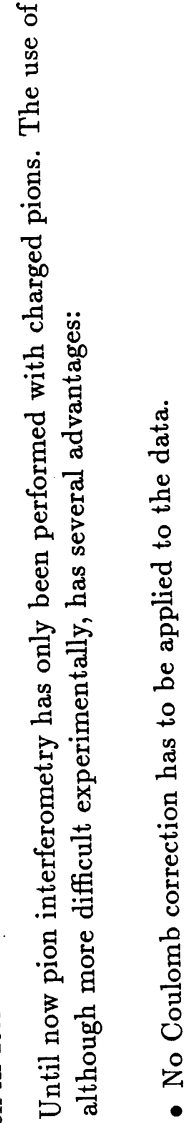



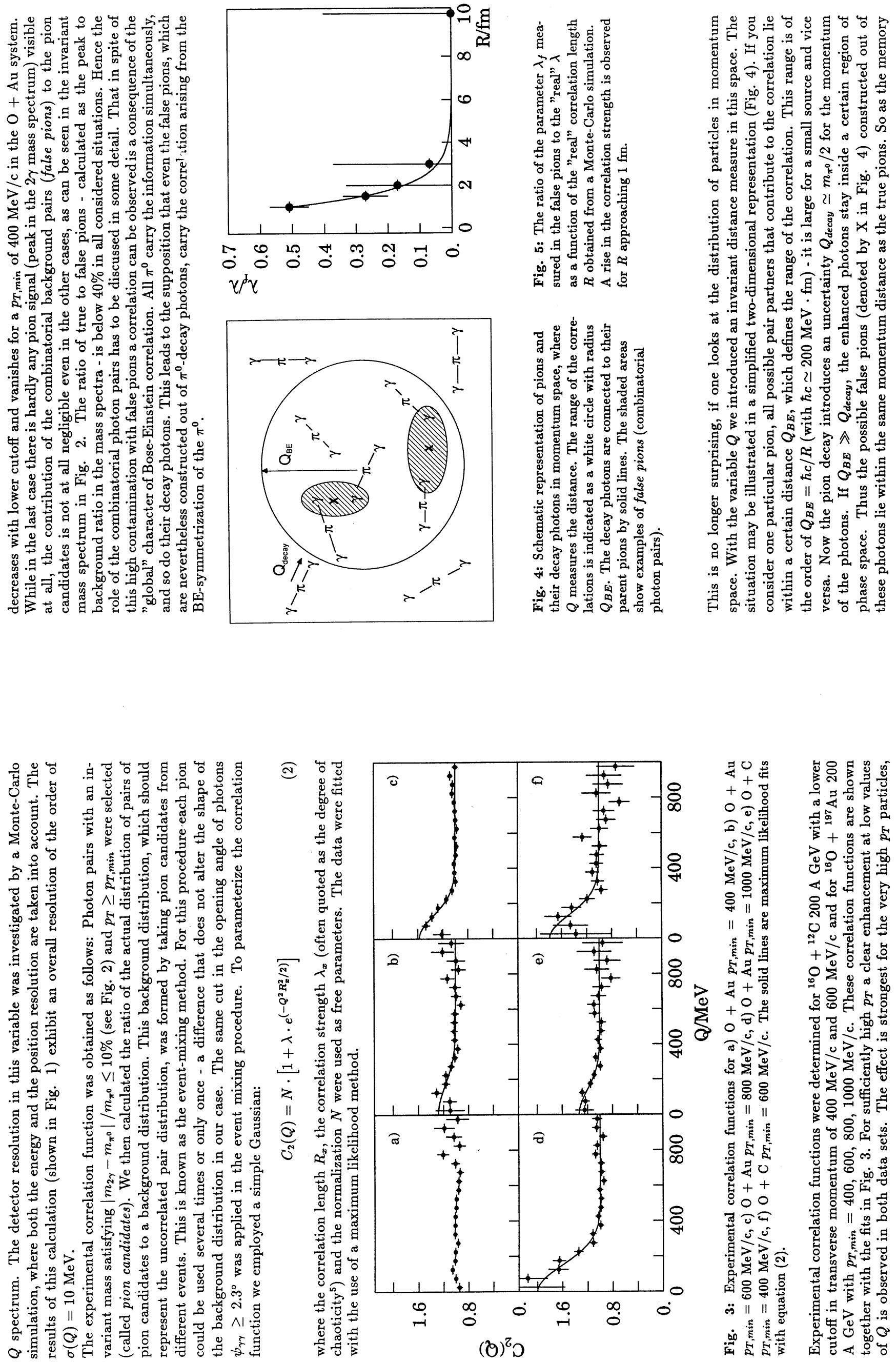

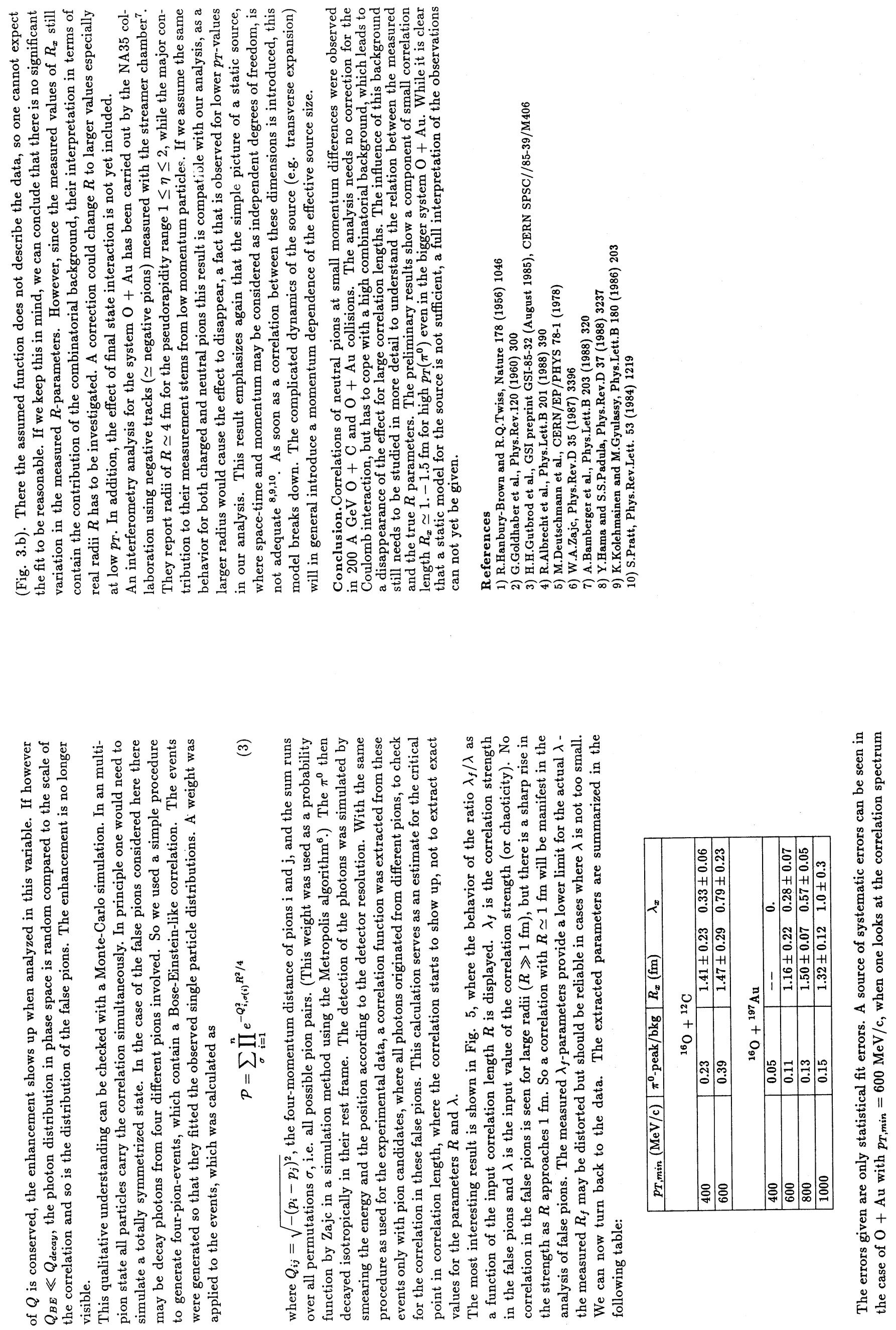